\title{
(2) OPEN ACCESS \\ Granulomatosis with polyangiitis presenting with unilateral facial nerve palsy and nasal septum perforation
}

\author{
Bandar Zaeri, Soha Khan, Asmaa Hegazy, Nayef Al Ghanim
}

Internal Medice Department, King Saud Medical City, Riyadh, Saudi Arabia

\section{Correspondence to} Dr Nayef Al Ghanim; n.alghanim@ksmc.med.sa

Accepted 17 December 2020

(c) BMJ Publishing Group Limited 2021. Re-use permitted under CC BY-NC. No commercial re-use. See rights and permissions. Published by BMJ.

To cite: Zaeri B, Khan S, Hegazy A, et al. BMJ Case Rep 2021;14:e236469. doi:10.1136/bcr-2020236469

\section{SUMMARY}

Granulomatosis with polyangiitis (GPA) is a necrotising vasculitis of unknown cause that has several systemic manifestations. The disease is characterised by the classical triad involving acute inflammation of the upper and lower respiratory tracts with renal involvement. However, the disease pathology can involve the central nervous system. This case report presents a case of GPA with facial nerve palsy as the first manifestation of the disease, which has been rarely reported in the medical literature.

\section{BACKGROUND}

Granulomatosis with polyangiitis (GPA) is a multisystem antineutrophil cytoplasmic antibody (ANCA)-associated autoimmune disease typified by inflammation, necrosis and vasculitis of the upper and lower airways and kidneys. Being a systemic disease, it may additionally involve any organ systems. GPA is a serious disease that can result in organ damage if not treated immediately. We have presented the case of a 17-year-old female patient with unilateral facial nerve palsy and nasal septum perforation.

\section{CASE PRESENTATION}

A 17-year-old female patient with a known case of bronchial asthma was admitted to the Department of Neurology, King Saud Medical City, Riyadh, Saudi Arabia, for an acute onset of seizure and headache that persisted for 5 days. Brain CT revealed no abnormality, and anti-epileptic agents were started. The doctors consulted the Department of Rheumatology because the patient had a history of joint pain and skin rash.

The patient's history was retrospectively explored. She further reported the following findings: history of fatigue, right-side facial palsy and right lower limb numbness for approximately 1 year; history of runny nose, nasal ulcers, epistaxis, tinnitus and unilateral right ear pain with a yellowish discharge for the last 6 months; history of productive cough with yellowish sputum and haemoptysis on one occasion and no fever or chest pain during the last 6 months; 7\% weight loss (body mass index $=28$ ) and poor appetite over the last 6 months; history of haematuria for the last 2 months and history of multiple joint pain involving the hips, knees and small joints of the hands associated with skin rash over the dorsum of the right foot. There was no family history of similar condition or any hereditary disease. Social history revealed that she is single, living with her family with good socioeconomic status, good academic performance and no history of smoking, alcohol or any substances abuse.

The general physical examination revealed noticeable facial asymmetry with a depressed nasal bridge, nasal ulcers, septal perforation, bilateral pitting pedal oedema (grade II) and petechial and purpuric skin rashes with haemorrhagic crust over the dorsum of the right foot (figure 1). The chest examination revealed bilateral fine crackles over the upper lobes. The neurological examination revealed right-sided lower motor neuron facial palsy grade IV according to the House and Brackmann scale. The remaining neurological and systemic examinations were normal.

Laboratory investigations uncovered elevation of acute-phase reactant parameters, including the erythrocyte sedimentation rate $(111 \mathrm{~mm} /$ hours) and C reactive protein level $(7.7 \mathrm{mg} / \mathrm{dL})$, in addition to evidence of normocytic anaemia (haemoglobin $=90 \mathrm{~g} / \mathrm{dL}$ ), leucocytosis (white cell count $=23 \times 10^{9} / \mathrm{L}$ ) and thrombocytosis (platelet count $=716 \times 10^{9} / \mathrm{L}$ ). The results of other biochemical investigations, including assessments of renal function, liver function, blood glucose levels and the thyroid profile, were normal. Bronchoscopy revealed no evidence of infection, haemorrhage or malignancy. Viral markers for HIV, hepatitis B and hepatitis $\mathrm{C}$ were negative. Routine microscopy of urine revealed proteinuria $(3+)$ and red blood cell casts. Accordingly, 24-hour urinary protein was measured, giving a result of $5.3 \mathrm{~g} /$ day. On further testing, rheumatoid factor and antinuclear factor were negative. However, c-ANCA was positive $54 \mathrm{AU} / \mathrm{mL}$ (anti-proteinase-3), p-ANCA was weakly positive $27 \mathrm{AU} / \mathrm{mL}$ (myeloperoxidase antibody) and anti-Glomerular Basement Membrane (BGM) was negative. Kidney biopsy revealed features suggestive of pauci-immune crescentic glomerulonephritis.

Chest X-ray uncovered multiple cavitary lesions (figure 2). Chest CT revealed multiple large thickwalled cavitating lesions (figure 3). Brain MRI revealed multifocal cortical swelling with bilateral opacification of the mastoid air cells (figure 4). CT of the paranasal sinus identified deviation of the nasal septum and chronic suppurative otitis media (figure 5). Bronchoscopy revealed no evidence of infection, haemorrhage or malignancy.

Based on these investigations and imaging findings, the patient was diagnosed with GPA. 


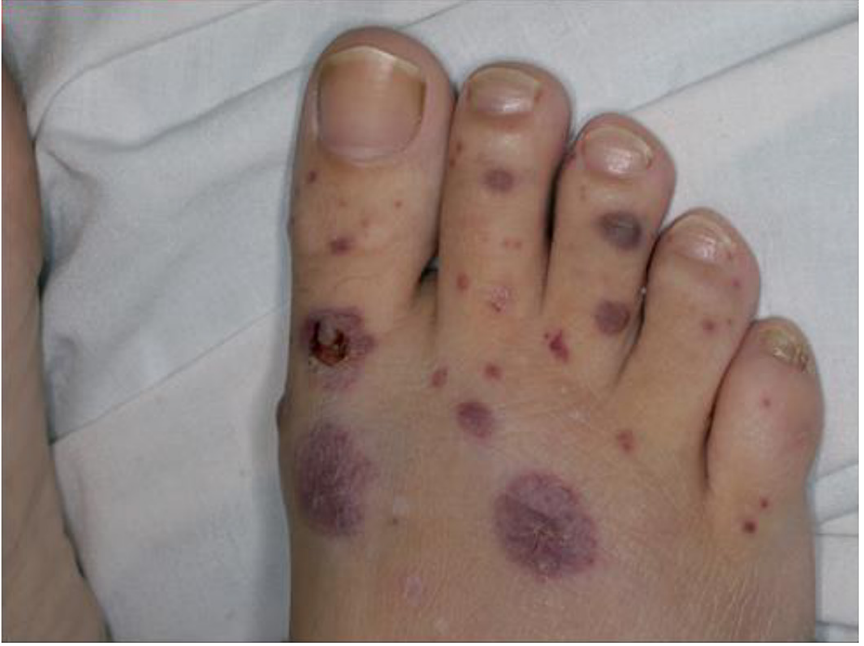

Figure 1 Purpuric papules and plaque on the dorsum of the right foot with pinpoint petechiae. Haemorrhagic crust on the right big toe.

\section{TREATMENT}

Treatment was started (1 week after presentation) according to the European Vasculitis Study Group protocol for the management of primary small and medium vessel vasculitis. Initially, she received three pulses of daily intravenous methylprednisolone (1 g) followed by intravenous cyclophosphamide at a dose of $1 \mathrm{~g}$ every month for a total of 6 months. In addition, the patient underwent plasmapheresis. She additionally received remission maintenance therapy using the combination of low-dose glucocorticoid $(0.25 \mathrm{mg} / \mathrm{kg})$ and azathioprine $(2 \mathrm{mg} / \mathrm{kg})$ for 18 months. She exhibited an excellent response to this combination treatment with a complete resolution of facial palsy, and marked improvement of other clinical findings. Antiepileptic therapy was started by the Department of Neurology, whereas an otolaryngologist performed reconstructive surgery (augmented septo-rhinoplasty by harvesting aurical cartilage) following a consultation.

\section{OUTCOME AND FOLLOW-UP}

The patient's symptoms improved markedly after 2 weeks of treatment initiation, and her facial asymmetry, tinnitus and right ear discharge disappeared. Her

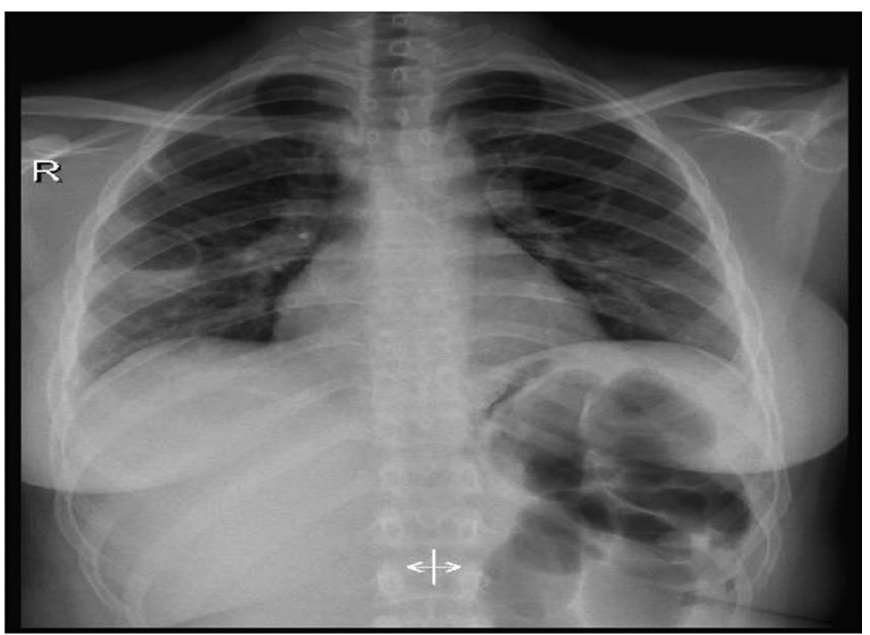

Figure 2 Chest X-ray identified multiple cavitary lesions.

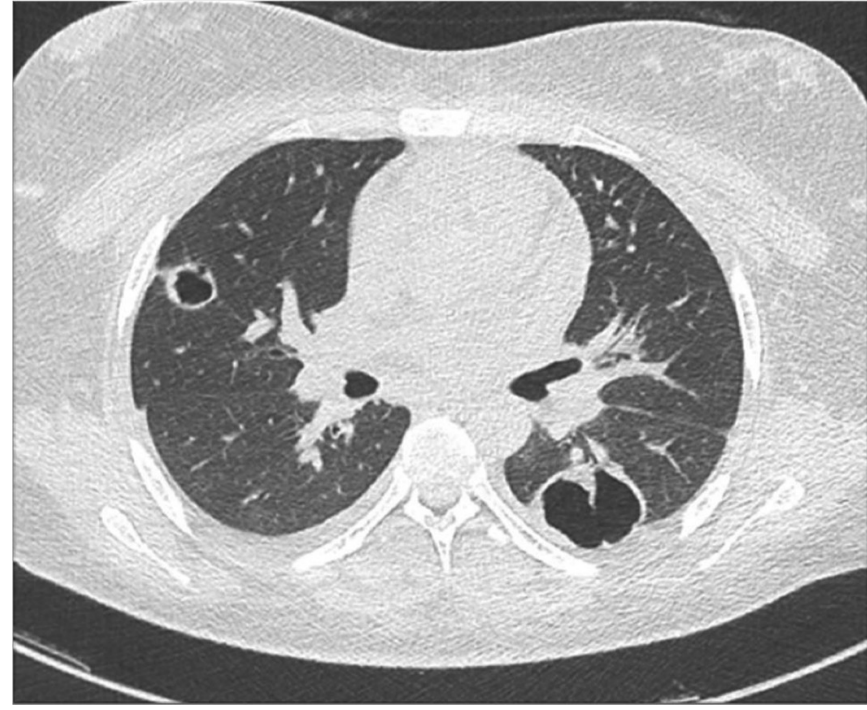

Figure 3 High-resolution chest CT without intravenous contrast revealed multiple large thick-walled cavitating lesions in both upper lobes with post-fibrotic bronchiectatic changes. Another large cavity was present in the left lower lobe, and multiple small cavitary lesions were observed in the right middle lobe and superior segment of the right upper lobe. No pleural thickening or effusion was noted.

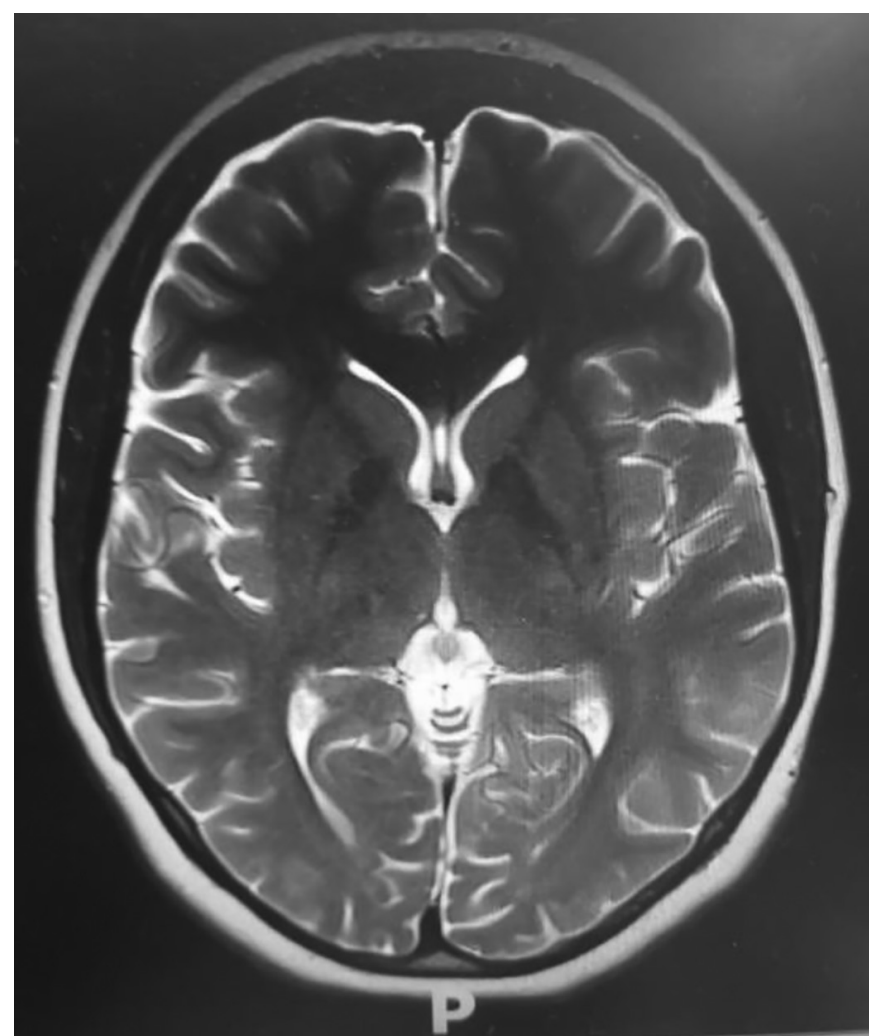

Figure 4 Brain MRI revealed multifocal cortical swelling with adjacent subcortical high-signal intensities on T2 and Fluid attenuated inversion recovery (FLAIR) images with faint diffusion restriction involving the right frontal, parietal and occipital lobes, bilateral opacification of the mastoid air cells in line with otomastoiditis and partial opacification of the visualised paranasal sinuses. 


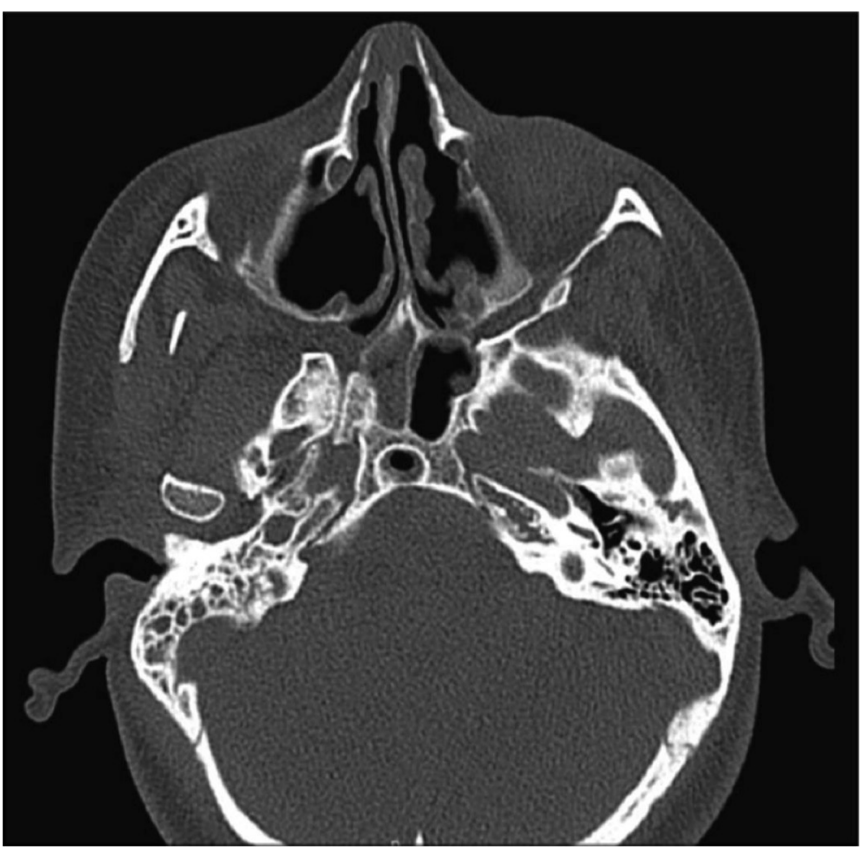

Figure 5 CTof the paranasal sinuses. The nasal septum was deviated to the left side. Residual mild mucosal thickening was observed in the bilateral ethmoid, sphenoid and maxillary sinuses, in addition to rightsided chronic suppurative otitis media.

repeated 24-hour urine protein was $398 \mathrm{mg} / \mathrm{day}$ and 100 $\mathrm{mg}$ /day after 2 and 5 months of treatment, respectively.

\section{DISCUSSION}

GPA, previously known as Wegener's granulomatosis, is an uncommon systemic disease and ANCA-associated vasculitis involving small-sized and medium-sized vessels of the lungs and kidneys. ${ }^{23}$ The prevalence of GPA is approximately 3 per 100000 people. ${ }^{4}$ The mean age of presentation of GPA in European and American populations is 50 years, compared with 40 years in India, ${ }^{5}$ whereas our patient presented at 17 years of age, which is uncommon. C-ANCA and anti-PR3 autoantibody positivity are diagnostic markers of GPA that are present in 70\%-90\% of patients, including our patient. ${ }^{6}$ Our patient was also positive for p-ANCA MPO+, which is unusual in GPA, although it has been reported in 5\%-10\% of patients. ${ }^{6}$ GPA usually presents with head, neck, pulmonary and renal manifestations. ${ }^{4}$

The most common primary manifestation in GPA is ear-nosethroat system involvement, ${ }^{4} 7$ and nasal and paranasal sinus disorder is observed in $90 \%$ of patients. ${ }^{4}$ The signs and symptoms may include rhinitis, sinusitis, mastoiditis, ulcers or granulomatous inflammation of the nose, subglottic stenosis, bone and cartilage destruction resulting in saddle nose deformity, epistaxis and otitis media. ${ }^{38}$ Our patient presented with rhinitis, nasal ulcers, epistaxis, septal perforation, saddle nose deformity and unilateral chronic suppurative otitis media. Cannady et al reported incidences of septal perforation and saddle nose deformity of $33 \%$ and $23 \%$, respectively, in patients with GPA. ${ }^{8}$

Tracheal and pulmonary involvement, including pulmonary infiltrates or nodules, is the second most common manifestation. ${ }^{4}$ Patients with GPA may exhibit airway or pulmonary parenchyma involvement causing hoarseness, cough, dyspnoea, stridor, wheezing, haemoptysis or pleuritic pain. These symptoms may be accompanied by signs of tracheal or subglottic stenosis, pulmonary consolidation and/or pleural effusion. The chest radiographic findings are variable, and common manifestations include nodules, patchy or diffuse opacities and fleeting pulmonary infiltrates and hilar adenopathy. ${ }^{9-11}$ Our patient presented with haemoptysis and cavities, which can occur in up to $50 \%$ of patients. ${ }^{12}$

Meanwhile, only $18 \%$ of patients have renal involvement at presentation, but $77 \%-85 \%$ of patients ultimately develop renal disease, usually within the first 2 years of disease onset. ${ }^{9}{ }^{13}$ Signs and symptoms may include glomerular haematuria with or without red blood cell casts, proteinuria, rapidly progressive glomerulonephritis and end-stage renal disease. ${ }^{913}$ Our patient presented with glomerular haematuria and proteinuria, and her 24-hour urinary protein level was $5.3 \mathrm{~g} /$ day.

Approximately one-half of patients with GPA have cutaneous manifestations. ${ }^{14}$ The most common skin lesion is leucocytoclastic angiitis, which causes purpura involving the lower extremities that may be accompanied by focal necrosis and ulceration. ${ }^{14}$ Skin lesions may also include urticaria, livedo reticularis and nodules. ${ }^{14}$ Our patient presented with a petechial and purpuric rash with ulceration over the dorsum of the right foot.

Nervous system involvement has been reported in approximately $20 \%-50 \%$ of patients with GPA. ${ }^{3} 15$ Three theories explaining central nervous system involvement are (a) vasculitis of the nervous system; (b) contiguous invasion of granuloma from extracranial sites and (c) remote intracranial granuloma. ${ }^{16-18}$ The peripheral nervous system may be involved if vasculitis progresses to vasa nervorum, which may cause cranial nerve palsy as found in our patient. The signs and symptoms may include mononeuritis multiplex, sensory neuropathy, cranial nerve abnormalities, central nervous system mass lesions, meningeal disease, external ophthalmoplaegia and sensorineural hearing loss. ${ }^{1719}$ The signs of neurologic dysfunction in our patient included headache, seizure, right-sided facial nerve palsy and right lower limb numbness. There are a few reports of bilateral facial nerve palsy, ${ }^{47}$ whereas unilateral facial nerve palsy is rare. A case report by Ujjawal, Koushik, Ajay and Subrata described a patient who presented with left-sided lower motor neuron facial palsy in the absence of any systemic symptoms or signs, ${ }^{2}$ whereas our patient presented with unilateral facial nerve palsy associated with signs and symptoms of multi-organ involvement. Thus, we have presented the first case of a young patient with GPA who presented with unilateral facial palsy in Saudi Arabia.

GPA is an autoimmune disease that can be lethal if left untreated. Long-term remission can be achieved in up to $90 \%$ of patients via treatment with immunosuppressive agents such as steroids and cyclophosphamide. ${ }^{20}$ Further studies are needed to identify patients with unilateral facial palsy given its rarity. Physicians should be aware of the atypical and varied presentation of this disorder in an effort to facilitate early diagnosis and treatment.

\section{Twitter Bandar Zaeri @Dr_b_z}

Contributors Patients care: BZ, SK and AH. Conception and design, acquisition of data or analysis and interpretation of data: BZ, SK and AH. Drafting the article or revising it critically for important intellectual content: BZ, SK and AH. Final approval of the version published: NAG. Agreement to be accountable for the article and to ensure that all questions regarding the accuracy or integrity of the article are investigated and resolved: NAG.

Funding The authors have not declared a specific grant for this research from any funding agency in the public, commercial or not-for-profit sectors.

Competing interests None declared.

Patient consent for publication Parental/guardian consent obtained. 


\section{Patient's perspective}

I was very sick, I was not able to sleep due to my cough and headache and was unable to do my routine activities as I usually would. I was not knowing the exact diagnosis and was visiting various medical institutions. Treatment with antibiotics and analgesics did not provide relief. There were also concerns about tuberculosis and cancer.

However, an accurate diagnosis was provided at the hospital, and the prescribed treatment was initiated. After the initiation of treatment, the symptoms completely cleared. I am feeling fine and have had no complications so far. I have started to do my routine activities without any limitations. I am grateful for my doctor.

\section{Learning points}

- Granulomatosis with polyangiitis (GPA) can present with different neurological manifestations.

- Careful history and physical examination are helpful for the identification of unusual presentation of autoimmune diseases.

- Aggressive treatment of GPA is indicated in patients with major organ involvement.

- Early aggressive treatment can prevent end-organ damage.

Provenance and peer review Not commissioned; externally peer reviewed.

Open access This is an open access article distributed in accordance with the Creative Commons Attribution Non Commercial (CC BY-NC 4.0) license, which permits others to distribute, remix, adapt, build upon this work non-commercially, and license their derivative works on different terms, provided the original work is properly cited and the use is non-commercial. See: http://creativecommons.org/ licenses/by-nc/4.0/.

\section{REFERENCES}

1 Gupta V, Sharma AK, Sureka RK, et al. Chronic meningitis with multiple cranial neuropathies: a rare initial presentation of Wegener's granulomatosis. Ann Indian Acad Neurol 2013;16:411-3.
2 Ujjawal R, Koushik P, Ajay P, et al. A case of Wegener's granulomatosis presenting with unilateral facial nerve palsy. Case Rep Med 2016;2016:1-3.

3 Fragoulis GE, Lionaki S, Venetsanopoulou A, et al. Central nervous system involvement in patients with granulomatosis with polyangiitis: a single-center retrospective study. Clin Rheumatol 2018;37:737-47

4 Jeong SM, Park JH, Lee Jl, et al. Progressive bilateral facial palsy as a manifestation of granulomatosis with polyangiitis: a case report. Ann Rehabil Med 2016;40:734-40.

5 Sharma A, Naidu GSRSNK, Rathi M, et al. Clinical features and long-term outcomes of 105 granulomatosis with polyangiitis patients: a single center experience from North India. Int J Rheum Dis 2018;21:278-84.

6 Terebelo S, Chen I. Granulomatosis with polyangiitis presenting as pyrexia of unknown origin, leukocytosis, and microangiopathic haemolytic anemia. Case Rep Rheumatol 2017;2017:1-6.

7 Wawrzecka A, Szymańska A, Jeleniewicz R, et al. Granulomatosis with polyangiitis with bilateral facial palsy and severe mixed hearing loss. Case Rep Otolaryngol 2016;2016:1-4.

8 Cannady SB, Batra PS, Koening C, et al. Sinonasal Wegener granulomatosis: a singleinstitution experience with 120 cases. Laryngoscope 2009;119:757-61.

$9 \mathrm{Seo}$ P, Stone JH. The antineutrophil cytoplasmic antibody-associated vasculitides. Am J Med 2004; 117:39-50.

10 Langford CA, Sneller MC, Hallahan CW, et al. Clinical features and therapeutic management of subglottic stenosis in patients with Wegener's granulomatosis. Arthritis Rheum 1996;39:1754-60.

11 Gómez-Puerta JA, Hernández-Rodríguez J, López-Soto A, et al. Antineutrophil cytoplasmic antibody-associated vasculitides and respiratory disease. Chest 2009;136:1101-11.

12 Martinez F, Chung JH, Digumarthy SR, et al. Common and uncommon manifestations of Wegener granulomatosis at chest CT: radiologic-pathologic correlation. Radiographics 2012;32:51-69.

13 Haas M, Eustace JA. Immune complex deposits in ANCA-associated crescentic glomerulonephritis: a study of 126 cases. Kidney Int 2004;65:2145-52.

14 Marzano AV, Raimondo MG, Berti E, et al. Cutaneous manifestations of ANCAassociated small vessels vasculitis. Clin Rev Allergy Immunol 2017;53:428-38.

15 Huang Y-H, Ro L-S, Lyu R-K, et al. Wegener's granulomatosis with nervous system involvement: a hospital-based study. Eur Neurol 2015;73:197-204.

16 Asakura K, Muto T. [Neurological involvement in Wegener's granulomatosis]. Brain Nerve 2013:65:1311-7.

17 Lučić AT, Veselinović M, Pantović S, et al. Granulomatosis with polyangitis (Wegener's) and central nervous system involvement: case report. Srp Arh Celok Lek 2015;143:83-6.

18 Seror R, Mahr A, Ramanoelina J, et al. Central nervous system involvement in Wegener granulomatosis. Medicine 2006;85:53-65.

19 Kang DH, Anderson S, Kim YG, et al. Impaired angiogenesis in the aging kidney: vascular endothelial growth factor and thrombospondin-1 in renal disease. Am J Kidney Dis 2001;37:601-11.

20 Celebi ZK, Kucuksahin O, Peker E, et al. Central nervous system involvement under intensive immunosuppressive treatment in a patient diagnosed with granulomatosis polyangiitis: a case report. Bantao J 2015;13:48-50.

Copyright 2021 BMJ Publishing Group. All rights reserved. For permission to reuse any of this content visit

https://www.bmj.com/company/products-services/rights-and-licensing/permissions/

BMJ Case Report Fellows may re-use this article for personal use and teaching without any further permission.

Become a Fellow of BMJ Case Reports today and you can:

- Submit as many cases as you like

- Enjoy fast sympathetic peer review and rapid publication of accepted articles

- Access all the published articles

- Re-use any of the published material for personal use and teaching without further permission

Customer Service

If you have any further queries about your subscription, please contact our customer services team on +44 (0) 2071111105 or via email at support@bmj.com.

Visit casereports.bmj.com for more articles like this and to become a Fellow 